\title{
A PRELIMINARY REPORT ON THE TREATMENT OF SYPHILIS COMPLICATING PREGNANCY*
}

\author{
By Alfred C. Beck, M.D., Brooklyn, N. Y. \\ From the Department of Gyneculogy and Obstetrics of The Long Istand College \\ Hospital.
}

QINCE the establishment of our prenatal clinic in 1912, mueh con$D$ sideration has been given to the subject of syphilis in pregnant women. At first very little was accomplished because our lack of laboratory facilities compelled us to rely solely upon the history and physical findings for diagnosis. Only rarely was it possible to obtain a history of the common symptoms of this complication. Physical examination likewise was of very little help and a positive diagnosis seldom was made except in those patients whose previous pregnancies ended in miscarriages or premature stillbirths.

Five years ago access to a Wassermann laboratory was obtained and the serological test of each patient was added to our routine. About 6 per cent of the applicants to our clinic showed a 3-plus or a 4-plus reaction. The addition of these facilities was a great aid in the cases that applied for care early in their pregnancies. As the majority of our patients came to us in the last trimester, satisfactory results were exceptional since insufficient funds forced us to depend upon mercury alone in the treatment of this condition.

In 1919 funds for the administration of salvarsan were obtained and it was possible to give our syphilitic patients intensive treatment. While the number of cases seen since the establishment of the free salvarsan clinic is small, the results have been so striking that your chairman has asked me to present them for your consideration. Thirty-two patients have been followed up after confinement. The accompanying Summary of Cases gives brief details of each case.

\section{DIAGNOSIS}

The history of symptoms and physical examination were of little service in making the diagnosis. Of the thirty-two patients only two gave the history of a rash. Two had sorcs on the vulva. One showed mucous patches and another had tabes. History of symptoms and physical examination aided in the diagnosis of only six, or 18.7 per cent of the total cases.

The history of the previous pregnancies was more valuable. Six-

*Read at a meeting of the Section on Obstetrics and Gynecology of the New Yotk Acadetry of Medicine, April 26, 1921 . 
teen, or 61.5 per cent, of the patients who had previous pregnancies, gave a history of miscarriages, stillbirths or living syphilitic infants and the characteristic tendency to carry each pregnancy further than the preceding ones was noted in seven. Eleven never had a miscarriage or stillbirth but always gave birth to living infants. After deducting from these eleven cases, three $(8,13$, and 14) in which the diagnosis is open to question on account of its having been based solely upon Wassermann findings, there remain eight, or 34.7 per cent, of the multiparae who carried all of their pregnancies to viability and gave birth to living infants of whom the majority probably were syphilitic. This high percentage of living infants born to untreated syphilitic mothers emphasizes the importance of disregarding a negative previous pregnancy history. It also shows the value of the routine Wassermann as well as the need for a microscopic examination of every placenta for syphilis. If private patients object to the examination of their blood during pregnancy the placenta at least may be examined in order that these unsuspected cases of congenital syphilis may be recognized and treated early.

The routine Wassermann test has been of great assistance. In our earlier work a single test was made. Lately we have had all positive reactions checked in the same or a different laboratory. All of the cases included in this report gave a strongly positive reaction. The Wassermann during pregnancy at times has been confusing and in several instances patients who have had no treatment showed a 3-plus or a 4-plus reaction during pregnancy and a negative one after deliv. cry. This experience has led me to be extremely careful in making a diagnosis upon Wassermann evidence alone. The seven cases marked with an asterisk in the accompanying Summary of Cases were diagnosed as syphilis solely upon Wassermann findings during pregnancy. Four of these occurred early in the series and as a result only one blood examination was made. The remaining three had repeated positive reactions. While it is possible that some of the seven patients were not syphilitie, it is probable thal niost of them were infected. My reason for including these questionable cases in this report is the fact that they introduce the question of the justifiability of intensive antisyphilitic treatment when the only evidence of syphilis is the presence of a positive Wassermann during pregnancy.

\section{TREATMENT}

The plan of treatment followed in this series consistcd of the administration of salvarsan and mercury as soon as the diagnosis was made. Four decigrams of salvarsan and one mereury injection were given weekly for six weeks. In addition the mercury was continued for six weeks more. If after these six salvarsan and twelve mercury in- 
jections the Wassermann test remained positive, a second similar course was repeated. One hundred and fifty-one intravenous salvarsan injections were given at various stages of pregnancy and in only one case was it necessary to discontinue the use of this drug because of unfavorable effects. The urine after treatment showed more than the occasional trace of albumin which is found during pregnancy. In those cases which were first seen too late in pregnancy to permit of the use of a full course of the drug, a few injections during the latter weeks were of great benefit. Following delivery, treatment was resumed as soon as the patients were able to return to the clinic.

All infants were referred to the department of pediatrics immediately after delivery. They received daily mercury rubs for two months. If the Wassermann test was negative one month later no turther treatment was given unless evidence of syphilis appeared. The infants of the patients who had not been given sufficient prenatal treatment and those in whom evidence of congenital syphilis was observed were treated more intensively. In addition to the daily rubs, 0.5 c.c. of mercury oxycyanate was administered weekly for six weeks at the end of which time intravenous salvarsan was commenced.

\section{END RESULTS}

In considering the end results I have divided the cases into three groups according to the amount of salvarsan administered before delivery. Group 1 contains four cases that received no salvarsan.

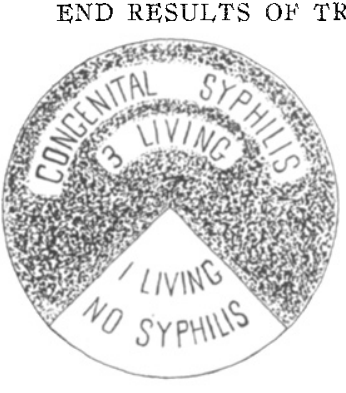

Fig. 1. -4 cases. No salvarsan before delivery.

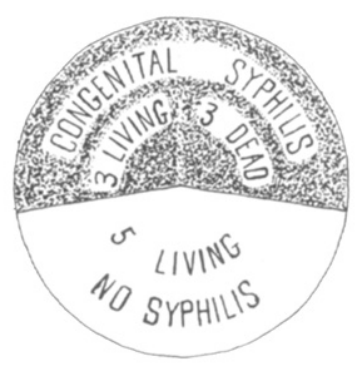

Fig. 2,-11 cases. 1-to-3 salvarsans before delivery.

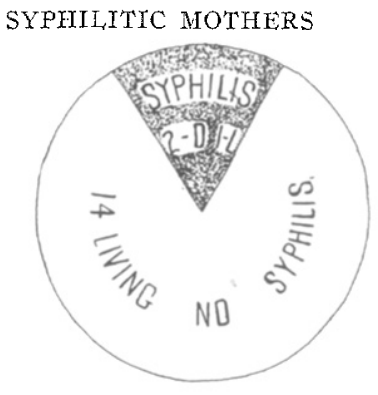

Fig. 3. -17 cases. 5t salvarsans before delivery.

Group 2 consists of eleven cases that had from one to three injections of this drug. Group 3 is made up of seventeen that had five or more injections. A graphic representation of the results in each group is shown in Figs. 1, 2, and 3 .

No salvarsan was given in Cases 2, 18, 31 and 32. All of these gave birth to living children. Two ( 2 and 31 ) had previous stillbirtlrs and the birth of living syphilitic infants in their cases was not unexpected. 
Case 32 in all probability contracted syphilis after her previous child was born. According to tradition, the birth of a living child in this case is unusual. However, as 34.7 per cent of our syphilitic multiparae had living infants without previous miscarriages or stillbirths, we do not look upon this as a very uncommon course. Al or soon after birth three of the four infants in this group showed signs of congenital syphilis. They have been under observation $4,6 \frac{1}{2}$ and 7 months, respectively, and have not responded to treatment as well as the syphilitic infants whose mothers had salvarsan before delivery. The fourth child has been observed for six months and has not revealed any of the stigmata of lues. Its mother's Wassermann was strongly positive before and after delivery. (See Fig. 1.)

One to three injections of salvarsan were given to eleven cases. Ten of these gave birth to living infants one of which died on the third day and another, a premature, died from pneumonia (?) two months after birth. Five of the remaining eight have been under observation $1 / 2,3,41 / 2,6$ and 16 months and have never shown any evidence of syphilis. The other three of the living infants in this group had congenital syphilis. They did well under treatment and had negative Wassermanns at 11, 11, and 13 months. (See Fig. 2.)

Five or more injections of salvarsan were given in seventeen cases. Fifteen gave birth to living infants and two miscarried at the fifth month. Fourteen of these infants have never shown any evidence of syphilis. (They have been under observation $1,1,1,2,2,4 \frac{1}{2}, 6,6,8$, $10,11,12,15$ and 18 months.) The one syphilitic child in this group is doing well under treatment. (See Fig. 3.)

Fourteen living and apparently nonsyphilitic infants from seventeen syphilitic mothers is a result that could not have been obtained even under the best circumstances when we relied upon mercury alone in the treatment of this condition. Even in the last weeks of pregnancy, when insulficient time remained for the administration of a full course of salvarsan, a few injections of this drug proved beneficial and the pediatricians who followed our cases observed that the lustic infants born to mothers who had these small amounts of salvarsan before delivery responded more readily than usual to antisyphilitic treatment.

\section{SUMMARY}

The history and physical examination were of little value in making: the diagnosis of syphilis. They aided in only six, or 18.7 per cent of the cases.

The history of the previous pregnancies was helpful in sixteen, or 61.5 per cent of the multiparae.

Eight unquestionably syphilitic multiparae carried all of their pre- 
vious pregnancies to the period of viability and gave birth to living infants, 34.7 per cent.

This high percentage of living infants born to untreated syphilitic mothers emphasizes the need for the routine prenatal Wassermann and the microscopic examination of every placenta.

If private patients object to the Wassermann test the placenta at least may be examined in order that early treatment in latent cases may be inaugurated.

The routine Wassermann test is a most valuable aid to prenatal work. This test, however, at times is misleading, for a positive reaction during pregnancy occasionally becomes negative after delivery, even though no treatment has been given.

Salvarsan may be given at any stage of pregnancy and its value is indicated by these results.

Eleven cases that received one to three injections gave birth to five living nonsyphilitic infants and three infected ones that have done remarkably well under treatment.

Seventeen cases that received five or more injections were delivered of fourteen nonsyphilitic and one syphilitic infant and the infection in the latter has been easily controlled by treatment.

I wish to acknowledge my indebtedness to the Genitourinary and Pediatric Departments of the hospital for their splendid cooperation in the care of these patients.

\section{SUMMARY OF CASES}

CASE 1.-U. J., age twenty-three, black, one five-months' miscarriage, two premature deliveries at 7 and $7 \frac{1}{2}$ months, no symptoms or signs of syphilis other than pregnancy history. Wassermann 4t, repeated 4t. Six injections of salvarsan and seven of mereury before delivery. Wassermann, after delivery, negative. Six. injections of salvarsan and five of mereury after delivery.

Child never showed any evidence of syphilis. Under observation $1 \frac{1}{2} 2$ years, at the end of which time its Wassermann was negative.

CASE 2.--M. S., age twenty-seven, white, two miscarriages at second and third months, one premature labor at $7 \frac{1}{2}$ monlis, une stillbirth. No symptoms or signs of syphilis, other then pregnaney history. Wassermann 4t, before delivery; no treatment. Child alive at birth; later developed a rash, a large spleen and suffered from inanition. At the end of six weeks its Wassermann was 4t. Intensive treatment given. Wassermann negative at the end of $5 \frac{1}{2}$ months. Last seen at the age of $61 / 2$ months, when it was doing well.

CASE 3.-M. H., age thirty-three, white, had three miscarriages and seven living infants. No symptoms $0 *$ signs of syphilis. Wassermann $4+$ before delivery. Six injections of salvarsan and five of mereury before delivery. Wassermann negative after delivery. Child born alive, and has never shown any signs of syphilis. Its Wassermann at $51 / 2$ months was negative. This infant has been under observation 10 months.

CASE 4.-M. M., age twenty-nine, white, one previous living child. Wassermann $4+$ before delivery. Repeated Wassermann 4t. Six injections of salvarsan and 
of mercury before delivery. Wassermann positive, after delivery. Child alive at birth. Its Wassermann negative at sixth week. No evidence of syphilis developed during the six months it has been under observation.

CASE 5.--L. B., white, primipara. No symptoms or signs of syphilis. Wassermann 4t. Six salvarsan and mercury injections before delivery. Child alive and has shown no signs of syphilis during the 14 months that it has been under observation.

CASR 6.-C. S., twenty-six, white, one living child. History of rash. Wassermann $3+$ before delivery. Repeated Wassermann $3+$. Two salvarsan and three mercury injections before delivery. Wassermann 3+ after delivery. Four salvarsan and mercury injections after delivery. Child alive, no evidence of syphilis at any time. Wassermann negative at sixteen months.

CASE 7.-P. S., seventeen, white, primipara, a prostitute. No symptoms or signs of syphilis other than $4+$ Wassermann. Five salvarsan and mereury injections before delivery; one salvarsan and twelve mereury injections after delivery. Child born alive and never showed any signs of syphilis. Age when last seen eight months.

CASE 8.-0. B., twenty-three, white, one living child, no symptoms or signs of syphilis other than 4t Wassermann. Six salvarsan and nine mercury injections before delivery. Child born alive and never showed any evidence of syphilis. Last seen at the age of eleven months.

CASE 9.-E. M., age twcnty-one, white, primipara, history of mucous patches, Wassermann 3t. Three salvarsan and two mercury injections before delivery. Five salvarsan and sixteen mercury injections after delivery. Premature child, 2200 grams, born alive but died at the age of two months in another hospital. Diagnosis. "Pneumonia."

CASE 10.-A. H., age thirty, white, two living, syphilitic elildren. No symptoms or signs of syphilis. Wassermann 3+, Repeat 3+. Six salvarsan and five mercury injections before delivery. Wassermann 2+, after delivery. Nineteen mercury injections after delivery. Child born alive and never showed any evidence of syphilis. Its Wassermann was negative at 15 months.

CASE 11.-A. B., thirty-four, white. One previous living child which died at three weeks. Wassermann 4t. Trepeat 4t. No other evidence of syphilis. One salvarsan and two mercury injections before delivery. Wassermann $4+$ after delivery. Five salvarsan and nineteen mercury injections after delivery. Child born alive, later developed rash, enlarged spleen and glands. Its Wassermann was negative at the age of 13 months.

CASm 12.-T. S., seventeen, white, primipara history of sore on vulva and prolonged sore throat. Wassermann 4.t. Repeat Wassermann 4t. Twenty salvarsan and eighteen mercury injections before delivery. Wassermann $3+$ after delivery. One salvarsan and nineteen mercury injections after delivery. Child born alive. Its Wassermann was negative at $31 / 2$ months. No evidence of syphilis was observed during the $4 \frac{1}{2}$ months it was under observation.

CASE 13.-E. W., twenty-nine, black, two living chilären. Wassermann 2+. Repeat $4+$. No other evidence of syphilis. One salvarsan and one mercury injection before delivery. Five salvarsan and seven mercury injections after delivery. Child born alive, under observation 6 months. Never showed any signs of syphilis.

CASE 14,-M. F., thirty-four, white, one miscarriage $6 \frac{1}{2}$ months, condylomata of vulva. Wassermann 2+. Repeat 4t. One salvarsan and two mereury injections before delivery. Child born alive and developed rash, snuffles and glands. Under observation 11 months. Doing well. 
CASE 15.-M. D., twenty-three, white, one 8-months' stillbirth, one living infant which died at the 6th week. Wassermann 4+. Repeat 4!. No other evidence of syphilis. Six salvarsan and nine mereury injections before delivery. Wassermann $3+$ after delivery. Tw0 mercury injections after delivery. Child born alive; later developed glands. Under observation 3 months. Doing well.

CASE 16.-E. T., twenty-one, black, one miscarriage, two stillbirths at 8 and 10 months. Wassermann 4t. Repeat 4t. No other evidence of syphilis. Three salvarsan and eight mercury injections before delivery. Wassermann $4+$ after delivery. Six salvarsan and vine mereury injections after delivery. Premature child, 2300 grams, born alive. Wassermann $2+$ at 2 months. Negative at 11 months. Under observation 19 months. Doing well.

Case 17.-E. T., twenty-two, black, same as Case 16. Wassermann 1\%. Six salvarsan and twenty-two mercury injections before delivery. Child born alive. Under observation 1 month. No evidence of syphilis.

CASE 18.-F. S., twenty-six, white, one living child. Wassermann 4t. Repeat 4+. No other evidence of syphilis. Two mercury injections before delivery. Was. sermann $4+$ after delivery. Child born alive. Never showed any signs of syphilis. Its Wassermann was negative at six months.

CASE 19.--A. M., thirty, black, primipara. Wassermann 4t. Repeat 3t. No other evidence of syphilis. Six salvarsan and fourteen mercury injections before delivery. Wassermann $4 \div$ after delivery. Six mereury injections after delivery. Child born alive. No evidence of syphilis. Wassermann negative at 6 months.

CASE 20.-A. L., thirty-five, white, one 8-months' stillbirth. Four dead children. Four living syphilitic children. Wassermam 4t. Repeat 4t. No other evidence of syphilis. Two salvarsan and one mereury injection before delivery. Wassermann $4+$ after delivery. Child born alive. Died on the third day. Syphilis.

CASE 21.-E. M., twenty-nine, white, one living syphilitic child. Wassermann 44. Repeat 4t. Patient has tabes dorsalis. Eight salrarsan and seventeen mercury injections before delivery. Wassermann 4t, after delivery. Four salvarsan and three mereury injections after delivery. Child born alive. Under observation 2 months. No evidence of syphilis.

OASE 22.--K. C., thirty-four, white, one stillbirth and four living children. Wassermann 4t. Repeat 4t. No other evidence of syphilis. One salvarsan and two mercury injections before delivery. Child full term, born dead. Syphilis.

CASE 23.-T. S., thirty-two, white, seven living ehildren. Wassermann 41. Repeat 4t. No other evidence of syphilis. Three salvarsan and one mercury injections before delivery. Wassemann $4+$ after delivery. Child born alive. Under observation 3 months. No evidence of syphilis.

CASE 24.-O. R., twenty-five, white, five living children. Wassermann 4t. Repeat $4+$. No other evidence of syphilis. Six salvarsan and seventeen mercury injections before delivery. Wassermann negative after delivery. Child born aive. Under observation one month. No evidence of syphilis. Wassermann negative.

CASE 25.-M. M., twenty, black, two miscarriages. Wassermann 4t. Repeat 4 . No other evidence of syphilis. Six salvarsan and nine mercury injections before delivery. Wassermann $4 \div$ after delivery. Child stillborn at the fifth month. Syphilis.

CASE 26.-G. P., twenty-six, white, two dead infants. Wassermann 4+. Repeat 4+. No other evidence of syphilis. One salvarsan and one mercury injection before delivery. Child born alive at term. Under observation 2 weeks. No evidence of syphilis. 
Cast 27.-0. N., eighteen, white, primipara. Wassermann 4t. Repeat 4t. No other evidence of syphilis. Two salvarsan and two mercury injections before delivery. Five salvarsan and nine mercury injections after delivery. Child born alive. Wassermann negative for $4 \frac{1}{2}$ months. Under observation $4 \frac{1}{2}$ months. No evidence of syphilis.

CASE 28.-M. J., twenty-two, white, one living 8-months' premature child. Died on eighth day. Wassermann 4t. Repeat 3t. History of a rash. Ten salvarsan and three mercury injections before delivery. Wassermann $3+$ after delivery. Child born alive. Under observation two months. No evidence of syphilis. Wassermann negative.

CASE 29.-S. S., twenty-one, white, one 8-months' premature infant which dicd. One full term living infant. Wassermann 2\%. Repeat 4\%. No other evidence of syphilis, Six salvarsan and seven mereury injections before delivery. Wassermann $4+$ after delivery. Four injections of salvarsan after delivery. Child stillbora at the 5th month. Syphilis.

Case 30.-L. R., thirty-two, white, one stillbirth. Wassermann 3\% Repeat $4+$. No other evidence of syphilis. Sixteen salvarsan and fifteen mercury injections before delivery. Child born alive. Wassermann negative at 12 months. Under observation 12 months. No evidence of syphilis.

CASE 31.-V. F., twenty-eight, white, one stillbirth at 8 months. Wassermann 4 . Repeat 4t. No other evidence of syphilis. No treatment before delivery. Child born alive. Developed snuffles, enlarged spleen, liver, glands, ete. Under observation 4 months. Doing well.

CASE 32.-F. C., twenty-four, white, one living ehild. Wassermann 4t. No treatment before delivery. Child born alive. Wassermann $4+$ at the $3 \mathbf{r d}$ month. Under observation 7 months. Epiphysitis of femur. Doing well.

20 LIVINGSTON STREET. 